\title{
Radiation resistance in Placozoa: Trichoplax adhaerens upregulates DNA repair genes and extrudes cells after exposure.
}

\author{
Angelo Fortunato ${ }^{1,2,3}$, Alexis Fleming ${ }^{1,2}$, Athena Akpitis ${ }^{1,4}$ and Carlo C. Maley ${ }^{1,2,3}$
}

1. Arizona Cancer Evolution Center, Arizona State University, 1001 S. McAllister Ave., Tempe, AZ, 85287, USA.

2. Biodesign Center for Biocomputing, Security and Society, Arizona State University, 727 E.

Tyler St.,Tempe, AZ 85281, USA.

3. School of Life Sciences, Arizona State University, 427 East Tyler Mall, Tempe, AZ 85287, USA.

4. Department of Psychology, Arizona State University, Tempe, AZ, USA. 


\begin{abstract}
Trichoplax adhaerens is the simplest multicellular animal with tissue differentiation and somatic cell turnover. Like all other multicellular organisms, it should be vulnerable to cancer, yet there have been no reports of cancer in T. adhaerens, or any other placozoan. We investigated the cancer resistance of $T$. adhaerens, discovering that they are able to tolerate high levels of radiation damage (240 Gy). To investigate how $T$. adhaerens survive levels of radiation that are lethal to other animals, we examined gene expression after the X-ray exposure, finding overexpression of genes involved in DNA repair and apoptosis including the MDM2 gene. We also discovered that $T$. adhaerens extrudes clusters of inviable cells after X-ray exposure. $T$. adhaerens is a valuable model organism for studying the molecular, genetic and tissue-level mechanisms underlying cancer suppression.
\end{abstract}




\section{Introduction}

Cancer is a problem for all multicellular organisms ${ }^{1}$. Generally speaking, somatic cells must limit their own proliferation in order for the organism to survive and effectively reproduce. Over the course of 2 billion years, multicellular organisms have evolved many mechanisms to suppress cancer, including control of cell proliferation. Complex multicellularity has evolved independently at least 7 times, and there is evidence of cancer-like phenomena on each of those 7 branches on the tree of life ${ }^{1}$. Although virtually every cell in a multicellular body has the potential to generate a cancer, and that risk accumulates over time, there is generally no association between body size or lifespan and cancer risk, an observation known as Peto's Paradox $^{2-5}$. This is likely because there has been selective pressure on large, long-lived organisms to evolve better mechanisms to prevent cancer than small, short-lived organisms ${ }^{6}$. This implies that nature has discovered a diversity of cancer suppression mechanisms, which we have only begun to explore for their applications to cancer prevention and treatment in humans ${ }^{7,8}$.

We used Trichoplax adhaerens (Placozoa) as our model organism for the present study. T. adhaerens is the simplest multicellular animal organism ever described (Fig.1). They are also ancient evolutionarily speaking, having diverged from other animals $\sim 800$ million years ago ${ }^{9} . T$. adhaerens is a disk-shaped, free-living marine organism, 2-3 mm wide and approximately 15 $\mu \mathrm{m}$ high. It is composed of only five somatic cell types, organized into three layers. $T$. adhaerens lack nervous and muscle tissues as well as a digestive system and specialized immune cells. They glide using the cilia of the lower epithelial layer. T. adhaerens feed on diatom algae by external digestion. In the laboratory, they reproduce only asexually through fission or budding ${ }^{10-}$ ${ }^{13}$ and they feed cooperatively ${ }^{14}$. T. adhaerens can detach from the plate surface when food is 
depleted and float on the water's surface. T. adhaerens can be collected from the natural world by placing slides in the water column where they are presumably floating ${ }^{15,16}$, suggesting that floating is part of the normal behavioral repertoire of T. adhaerens.

Other invertebrates, such as Caenorhabditis elegans and Drosophila melanogaster have been useful in molecular biology and the basic sciences ${ }^{17,18}$. However, they are not ideal models for cancer research because they do not have sustained somatic cell turnover, and so do not risk the mutations due to errors in DNA synthesis. In addition, their lifespans are very short, precluding the opportunity to develop cancer. T. adhaerens, on the other hand, have somatic cell turnover and very long lifespans - a single organism can reproduce asexually in the lab for decades (Petralia et al. 2014). Even with these factors that would typically predispose organisms to cancer - cell turnover and long lifespan - there have been no reports of cancer in T. adhaerens. In addition, the genome of $T$. adhaerens has been sequenced ${ }^{19}$, which enables us to analyze the evolution of cancer genes, detect somatic mutations and quantify gene expression. Despite $T$. adhaerens' being evolutionarily ancient, most of the known cancer genes in humans have homologs in T. adhaerens ${ }^{19}$.

It is an open question whether the lack of reports of cancer in T. adhaerens is due to a lack of studies or the ability of the animal to resist cancer. We set out to answer this question through exposing T. adhaerens to radiation and observing changes in their phenotypes and gene expression. By studying cancer resistance in T. adhaerens, it is possible to gain a window into the biological processes and the molecular mechanisms of cancer suppression that likely evolved in the earliest animals. 


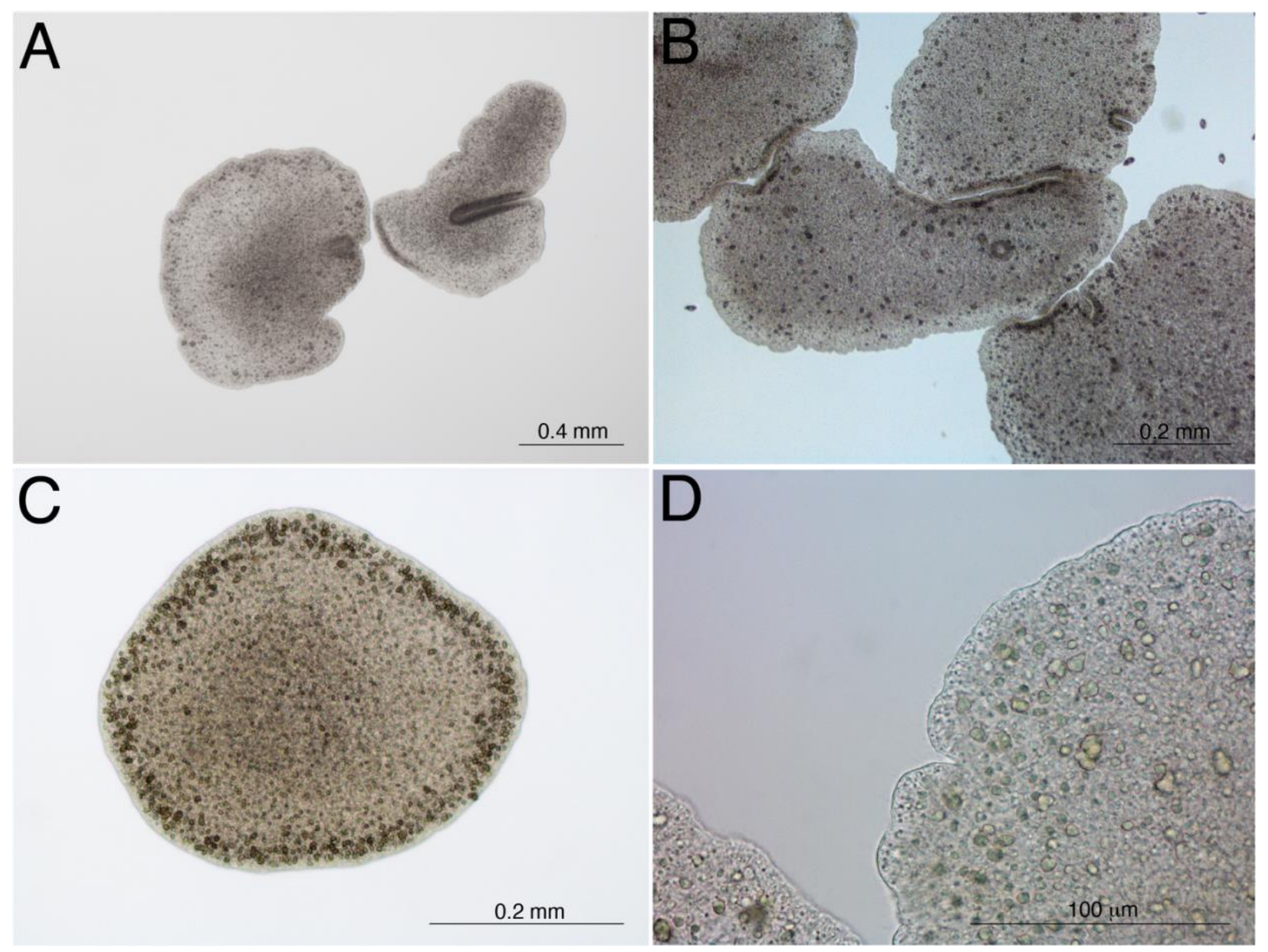

Figure 1. Trichoplax adhaerens is the simplest multicellular animal known to science,

containing only 5 cell types. They have a disk-like appearance, but they can assume different shapes and folds. A. Two specimens of $T$. adhaerens, the animal on the right is folding; B. $T$. adhaerens in close vicinity; C. Magnification of a single T. adhaerens; D. At high magnification cells are visible in vivo without staining.

\section{Material and methods}


Lab cultures. We grew T. adhaerens ${ }^{20}$ in glass Petri dishes $100 \mathrm{~mm}$ diameter $\mathrm{x} 20 \mathrm{~mm}$ high in $30 \mathrm{ml}$ of artificial seawater (ASW) made in the laboratory by adding 32.5 grams of Instant Ocean® sea salt (Prod. n. 77 SS15-10) per liter of distilled water, pH=8, at constant and controlled temperature $\left(23^{\circ} \mathrm{C}\right)$ and humidity $(60 \%)$ with a photoperiod of $14 \mathrm{hrs} / 10 \mathrm{hrs}$ light/dark cycle in an environmental chamber (Thermo Fisher Scientific, mod. 3940). We fed T. adhaerens with diatom algae (Pyrenomonas helgolandii) ab libitum. Each plate can contain hundreds of animals. When their numbers increase and when food is depleted, T. adhaerens detach from the plate surface and float on the water's surface. We gently collected the floating $T$. adhaerens with a loop and transferred them to new plates, along with $3 \mathrm{ml}$ of ASW from the old plate. This step is required for the animals to successfully grow in the new plates. The animal and algae cultures are assembled in a sterile environment using a biological hood and using sterile materials so that the cultures are protected from parasites and other microorganisms that might interfere with the maintenance of healthy cultures and experiments.

X-ray exposure. We transferred 50 floating animals in fresh plates with algae 3 days before exposure. On the day of exposure, any floating animals were removed from the plates. We exposed the animals to 160 Gy or 240 Gy using a Rad Source Technologies irradiator (mod. RS2000 Biological System). Considering X-ray absorbance of the borosilicate glass (Pyrex) plate lid $(2 \mathrm{~mm})$ and water in the column above the animals $(3 \mathrm{~mm})$, we calculated the actual X-ray exposure of specimens to be 143.6 Gy and 225.9 Gy respectively. We will refer to the irradiator setting values (160 Gy and $240 \mathrm{~Gy}$ ) hereinafter. To estimate the number of extrusions per animal and to monitor the morphological changes overtime, we transferred a single animal per well into 24 well-plates seeded 7 days before with algae ( $P$. helgolandii) of both control and experimental 
plates. Dose finding tests suggested that $240 \mathrm{~Gy}$ is the maximum single dose tolerance for $T$. adhaerens. After 30 days only a few animals $(<5 \%)$ survived but they repopulated the culture.

Morphological and morphometric analysis. We observed the animals under a Nikon SMZ1270 dissecting microscope and a Nikon Eclipse Ti-U inverted microscope. We recorded images and videos by using a Nikon DS-Fi2 camera. We counted the treated $(n=1085)$ and control $(n=992) T$. adhaerens and measured the size of the treated $(n=1085)$ and control $(n=992)$ animals present on the 10 plates of control and 10 plates treated replicas using ImageJ software 21. Images used for morphometric analysis were taken at 20X magnification.

DNA damage evaluation. We used the silver-stained Comet alkaline assay (Travigen ${ }_{\text {, }}$ Cat\#4251-050-K) ${ }^{22,23}$ to measure the level of DNA fragmentation according to the manufacturer's specifications and we used ImageJ software ${ }^{21}$ to quantify the DNA fragmentation.

Flow cytometry analysis. The human histone $\mathrm{H} 2 \mathrm{AX}$ protein is well conserved in $T$. adhaerens (TriadG64252, 82\% identity). In particular, serine 139 is present both in human and T. adhaerens protein (BLAST, ${ }^{24}$ ). Thus, we used the H2A.X Phosphorylation Assay Kit (Flow cytometry, Millipore, Catalog \# 17-344) to detect the level of phosphorylated (serine 139) histone H2AX. We collected 100 animals immediately after the X-ray exposure for each control and experiment replica (3 biological replicas of the experiment) in ASW. We then removed the ASW and we dissociated the cells in cold $\mathrm{Mg}^{++}$and $\mathrm{Ca}^{++}$free PBS with $20 \mathrm{mM}$ EDTA by gently pipetting the collected animals soon after adding the PBS-EDTA buffer. The samples were then kept on ice for 
5 minutes to ensure complete dissociation. We processed the dissociated cells according to the manufacturer's specifications and we quantified the level of phosphorylated histone $\mathrm{H} 2 \mathrm{AX}$ using an Attune ${ }^{\mathrm{TM}}$ NxT Flow Cytometer (Invitrogen ${ }^{\mathrm{TM}}$ ).

Gene expression analysis: RNA-seq. We treated the T. adhaerens with 240 Gy of X-rays. After 2 hours we extracted the total RNA (RNeasy ${ }^{\circledR}$ mini kit, Qiagen, cat. n. 74104) from 40 animals for each of the 3 experimental replicates (total, $n=120$ ) and respective controls (total, $n=120$ ). After verifying the purity and integrity of the RNA using an Agilent 2200 TapeStation, part of the extracted RNA was utilized for RNA-seq analysis in order to study the change in genetic expression between controls and experimental specimens at the level of the entire transcriptome. We sequenced the samples using an Illumina NextSeq 500 instrument. We checked the quality of the RNA-seq reads for each sample using FastQC v0.10.1 and we aligned the reads with the reference genome using STAR v2.5.1b (22.68 million reads uniquely mapped on average per sample). Cufflinks v2.2.1 was used to report FPKM values (Fragments Per Kilobase of transcripts per Million mapped reads) and read counts. TPM (Transcripts Per Million) was calculated using R software ${ }^{25}$. We performed the differential expression analysis using the EdgeR package from Bioconductor v3.2 in R 3.2.3. For each pairwise comparison, genes with false discovery rate $(\mathrm{FDR})<0.05$ were considered significant and $\log 2$-fold changes of expression between conditions were reported after Bonferroni correction. We analyzed the differentially expressed genes using Ensembl ${ }^{26}$ and PANTHER ${ }^{27}$ software.

Gene expression analysis: real-time PCR. We used the same RNA extracted for the RNA-seq analysis to validate the transcriptome analysis and we extracted the RNA (RNeasy ${ }^{\circledR}$ mini kit, 
Qiagen, Cat. No. 74104) at different times after being exposed to X-rays (2, 6, 12, 24, 48 hours) to study the expression of TriadG64021 (homolog of the human TP53 gene) and TriadG54791 (homolog of the human MDM2 gene). We extracted the RNA from 50 animals coming from 4 different plates exposed to 160 Gy X-rays and 4 control plates. Each experiment was repeated thrice. We assessed the RNA integrity through an Agilent 2200 TapeStation system. We retrotranscribed $400 \mathrm{ng}$ of RNA of each specimen using the SuperScript ${ }^{\circledR}$ Vilo $^{\mathrm{TM}} \mathrm{cDNA}$ synthesis kit (Invitrogen) according to the manufacturer's protocol. We used the SYBR green fluorescent dye (Power SYBR ${ }^{\circledR}$ Green, PCR master mix, Applied Biosystems) to monitor DNA synthesis. We reported the relative expression values for each gene as a ratio of the gene expression level to TriadT64020 (homolog of the human GAPDH gene) expression level in the same sample and normalized for the controls level of expression ${ }^{28,29}$.

We designed the primers using the software Primer3 ${ }^{30,31}$ (Tab.1S).

Whole genome sequencing (WGS). We collected 2 groups of specimens: Group 1 is composed by a specimen (parental), a small animal derived from an asymmetric fission of the parental animal and an extrusion derived from the parental specimen. Group 2 is composed by a specimen (parental) and an extrusion derived from the same animal. We collected the samples after 82 and 72 days, respectively from the X-ray treatment. We extracted the DNA using the NucleoSpin® Tissue XS kit (Takara, cat.n.740901.50) according to the manufacturer's specifications.

We generated Illumina compatible Genomic DNA libraries on Agilent's BRAVO NGS liquid handler using Kapa Biosystem’s Hyper plus library preparation kit (KK8514). We enzymatically sheared the DNA to approximately 300bp fragments, end repaired and A-tailed as described in the Kapa protocol. We ligated Illumina-compatible adapters with unique indexes 
(IDT \#00989130v2) on each sample individually. The adapter ligated molecules were cleaned using Kapa pure beads (Kapa Biosciences, KK8002), and amplified with Kapa’s HIFI enzyme (KK2502). Each library was then analyzed for fragment size on an Agilent's Tapestation, and quantified by qPCR (KAPA Library Quantification Kit, KK4835) on Thermo Fisher Scientific's Quantstudio 5 before multiplex pooling and sequencing a 2x100 flow cell on the NovaSeq platform (Illumina) at the Collaborative Sequencing Center.

We loaded $1500 \mathrm{pM}$ of the library pool with $1 \%$ PhiX for error tracking onto a NovaSeq SP flowcell for 101x8x8x101bp reads. Sequencing was performed using the Illumina NovaSeq 6000 SP Reagent Kit (200 cycles; cat\#20040326) on an Illumina NovaSeq 6000.

We checked the quality of WGS reads for each sample using FastQC v0.10.1 ${ }^{32}$ and aligned them to the T.adhaerens assembly deposited in DDBJ/EMBL/GenBank as accession number ABGP00000000 using Burrows-Wheeler short-read alignment tool, BWA-MEM version $0.7 .15^{33}$. After alignment, we discovered SNPs and indels following the GATK Best Practices workflow of germline short variant discovery ${ }^{34}$. We pre-processed raw mapped reads by adding read groups, indexing, marking duplicates, sorting, and recalibrating base quality scores. We called the variants using HaplotypeCaller ${ }^{35}$. We discarded according to their quality score $(\mathrm{Q}$ score $<30)$ and coverage $(<10 \mathrm{X})$. After discarding those regions, we obtained coverage of $10.1 \%$ (parental animal 1), 9.3\% (small asymmetric fission from parent 1), 2.7\% (extrusion 1), $28.7 \%$ (parental animal 2), and 7.6\% (extrusion 2). We annotated the variants by SnpEff (version $4.3 i)^{36}$.

\section{Results}


We found that $T$. adhaerens are able to tolerate high levels of radiation and are resilient to DNA damage. Exposure to X-rays triggered the extrusion of clusters of cells which subsequently died. We also found that radiation exposure induced the overexpression of genes involved in DNA repair and apoptosis.

T. adherens are radiation tolerant. T. adhaerens can tolerate 240 Gy maximum single dose Xray exposure. No T. adhaerens survived exposure to $280 \mathrm{~Gy}$ of X-rays. At $240 \mathrm{~Gy}$, less than $5 \%$ of the $T$. adhaerens survived (measuring the exact percentage is challenging because $T$. adhaerens divide and extrude cells during the experiment). These surviving T. adhaerens were able to repopulate the culture after 30 days of exposure to $240 \mathrm{~Gy}$. We observed morphological and behavioral changes after X-ray exposure, including blisters, changes in the shape of the animals, darker cellular aggregates and extrusion of clusters of cells (Fig. 2). These morphological changes were reversible in the animals that survived. T. adhaerens that survived also appeared to fully recover. 


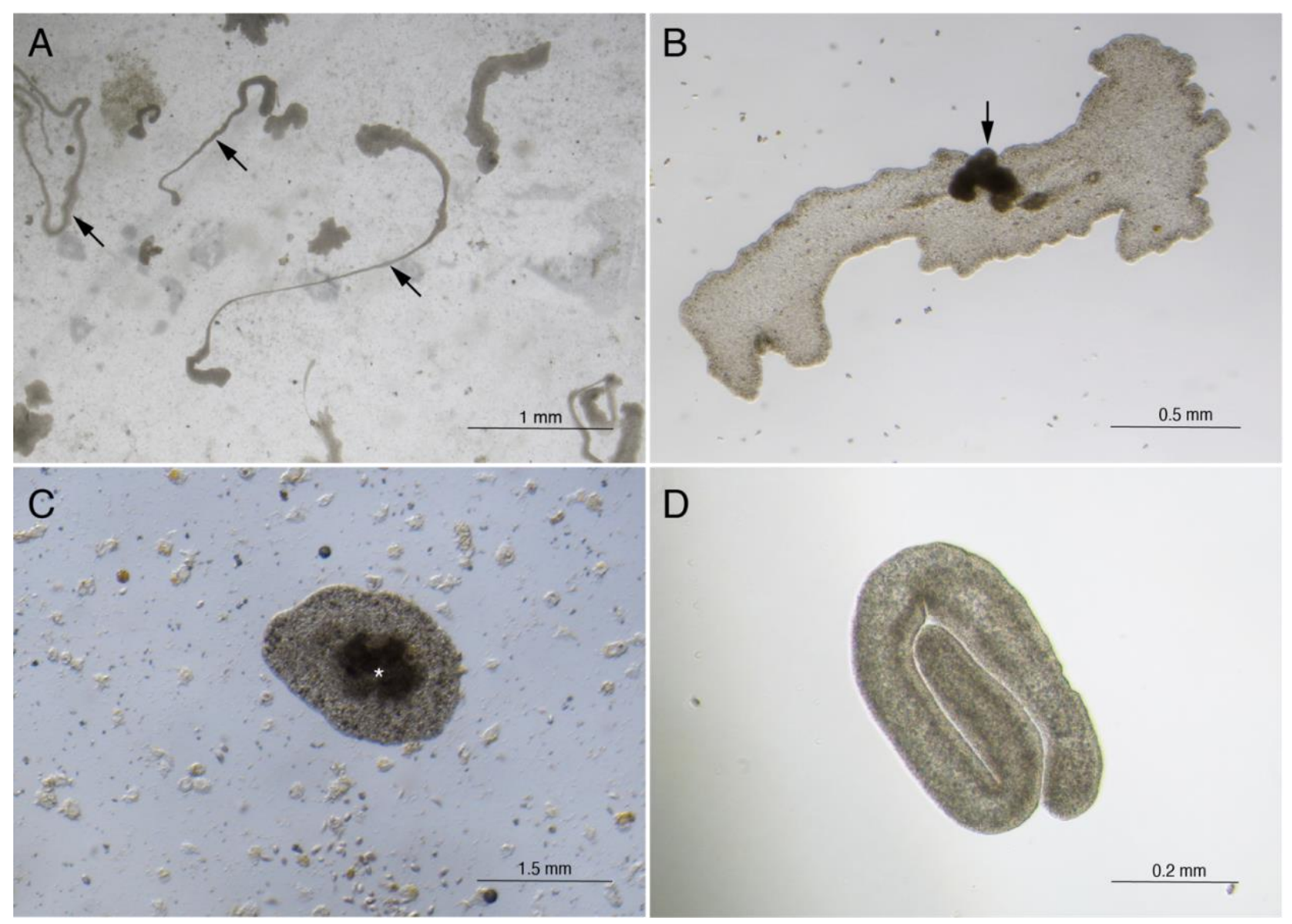

Figure 2. Radiation exposure causes morphological changes in T. adhaerens. A. Sections of the animals can become elongated (arrows), 20 days after 240 Gy exposure; B. Dark tissue mass projecting from the dorsal epitelium (arrow) of a T. adhaerens, 82 days after 160 Gy exposure;

C. Dark tissue mass (asterisk) in the middle of what is either a small animal or extrusion, 70 days after 160 Gy exposure; D. A folded T. adhaerens that is not moving, 36 days after 80 Gy exposure; this animal eventually recovered.

We found that the total number of discrete T. adhaerens entities (including both parents and extruded cells) rapidly increased through budding and fission immediately after X-ray irradiation (Repeated measurement ANOVA, P<0.01, Fig. 3) and their size significantly 
decreased (Repeated measurement ANOVA, $\mathrm{P}<0.0001$, Fig. 4), suggesting that the animals budded or divided without adequate physiological cell proliferation to regenerate their original size. After day 7, the total number of T. adhaerens in the treated group began to decrease (Fig. 3).

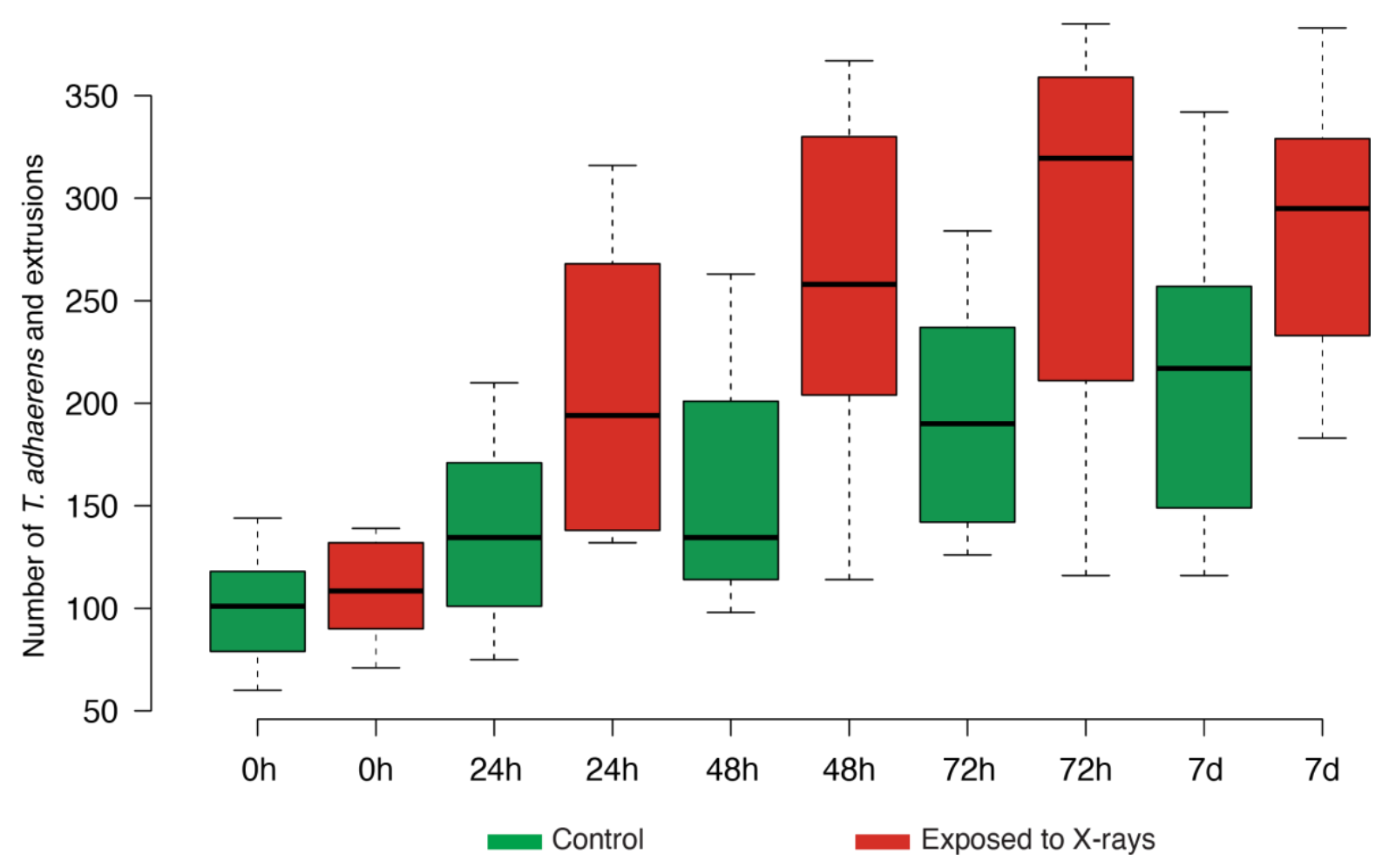

Figure 3. Number of T. adhaerens in control (green) and X-ray exposed experimental plates (red) before ( $0 \mathrm{~h}$ ) exposure, and then $24,48,72$ hours, and 7 days after exposure to 160 Gy of Xrays. T. adhaerens were counted under the microscope and the reported number is a combination of the organisms of all sizes including extrusions. 


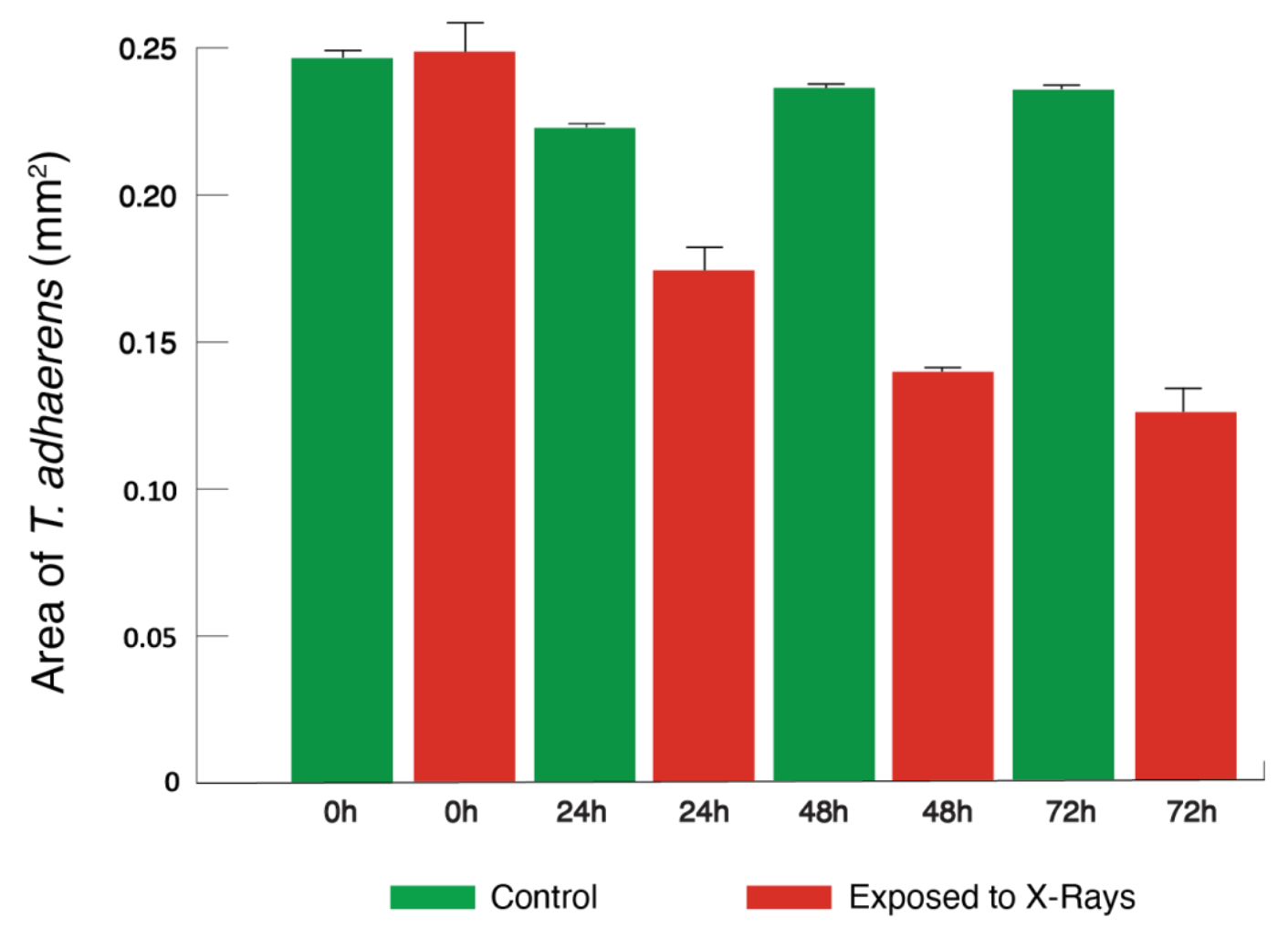

Figure 4. Size of T. adhaerens in T. adhaerens in control (green) and X-ray exposed experimental plates (red) before (0h), after 24, 48 and 72 hours $160 \mathrm{~Gy}$ of X-ray exposure. $T$. adhaerens were counted under the microscope, including extrusions. Histograms represent the mean \pm s.e.m. (error bars).

T. adhaerens extrude clusters of cells. The extruded bodies (Fig. 5) initially are flat and attached to the plates bottom but before dying they acquired a spherical shape (Fig. 2S). A week after X-ray exposure the dead extruded buds ( 65 out of 83 buds) from the experimental animals exceeded the number of dead buds ( 5 out of 71 buds) in the control (Fisher exact text, $\mathrm{P}<0.00001)$. In addition to regular buds, we observed extruded disk-shaped or spherical microbuds ( $\mathrm{n}=16, \varnothing=182.01 \mu \mathrm{m} \pm 23.40$ s.e.m.) in the experimental plates, but not in the control plates. 
These micro-buds are only visible at higher magnification and we did not include them in the number and size measurements of organisms presented in Figure 3 and 4.
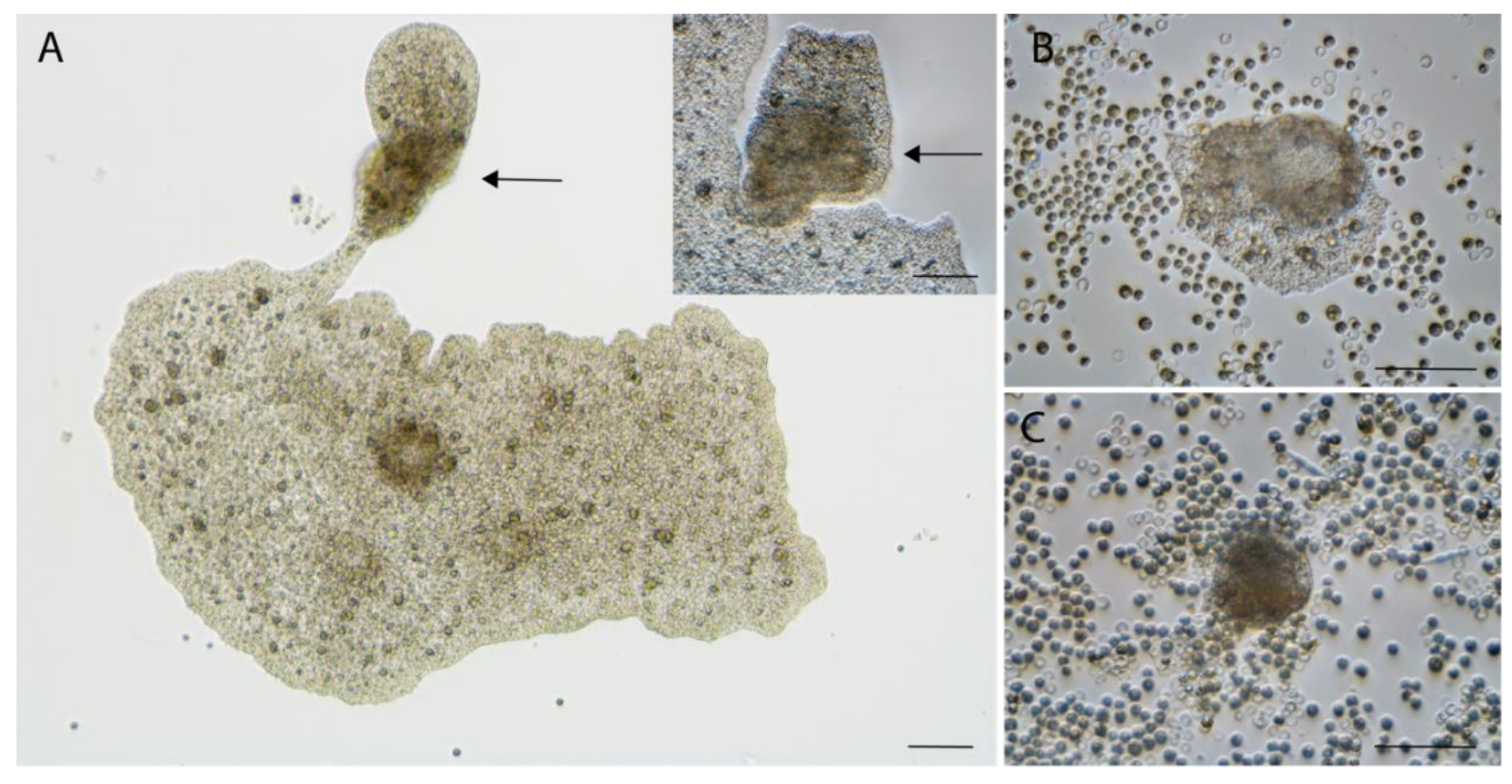

Figure 5. A. Extrusion (arrows) of brownish putative cancer-like cells; insert, magnification of the same extrusion. B. The cancer-like cells and the normal cells detached from the main body formed a new animal. The extrusion was observed and isolated 37 days after X-ray exposure. C. Over time the clear, apparently normal cells of the extruded body reduce in number, leaving only the apparently damaged cells which eventually died. This specimen was exposed to 160 Gy Xrays. A: bright field, insert, B and C: differential interference contrast (DIC), scale bars $=50 \mu \mathrm{m}$.

\section{T. adhaerens survive with extensive DNA damage}

We tested the animals with a Comet assay and found a catastrophic level of DNA fragmentation soon after a submaximal (160Gy) X-ray exposure (DNA fragmentation: treated $=94.46 \% \pm 0.54$ 
S.D. $(\mathrm{n}=77$ cells), controls $=13.83 \pm 8.15$ S.D. $(\mathrm{n}=81$ cells $)$, Mann-Whitney U Test, $\mathrm{P}<0.00001$,

Fig. 5). The H2AX assay confirmed DNA damage after X-ray exposure $(\gamma-\mathrm{H} 2 \mathrm{AX}$ positive cells:

treated $=43.70 \% \pm 13.36$ S.D., controls=21.37\% \pm 4.86 S.D., -test, $P=0.26$, Fig. $1 \mathrm{~S})$.

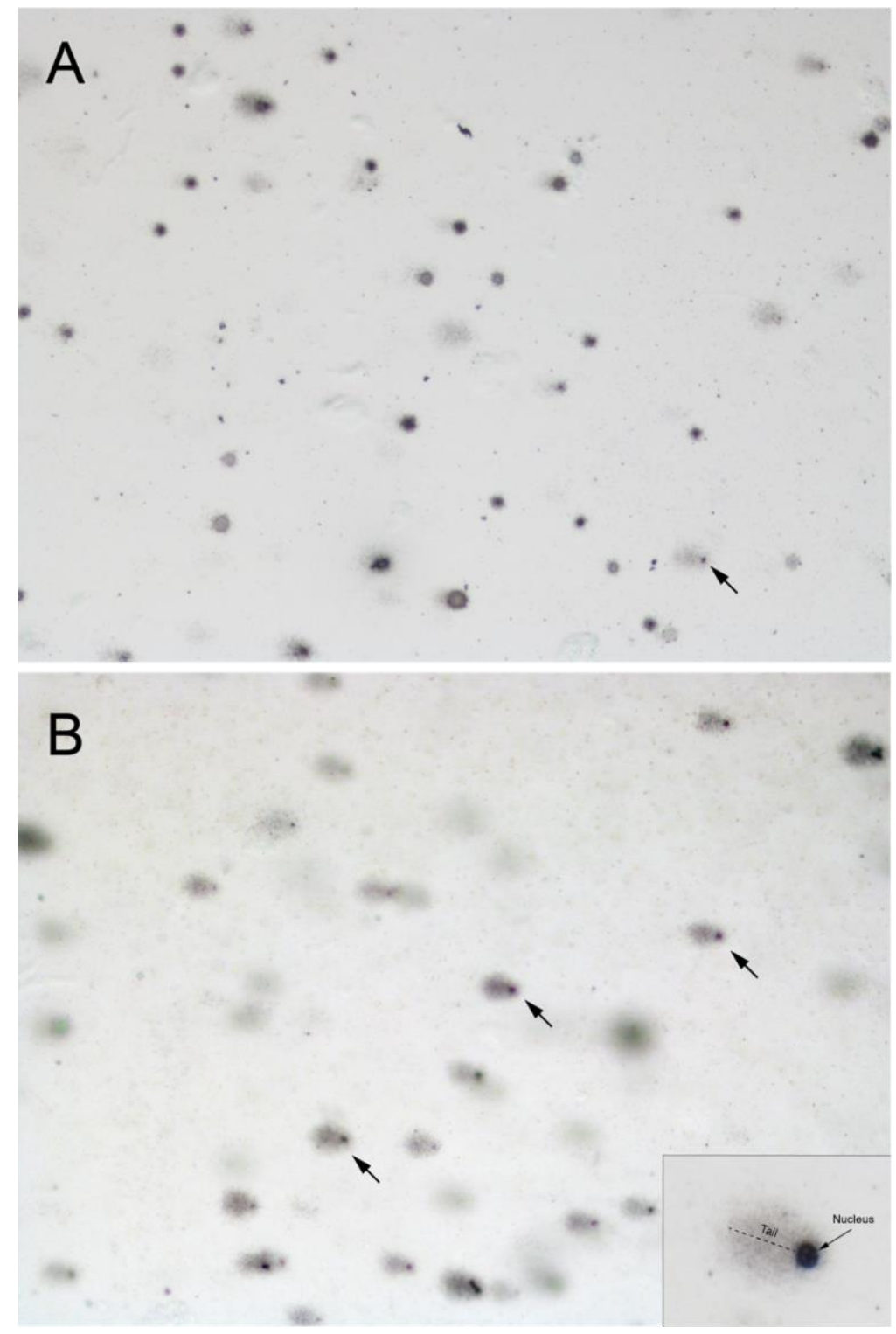

Figure 6. Representative images of the comet assay measuring DNA strand breaks. A. The controls have few nuclei showing DNA fragmentation. B. In contrast, animals exposed to 160Gy of X-rays have many more nuclei with extensive fragmentation of their DNA (Mann-Whitney U 
Test, $\mathrm{P}<0.0001)$. The arrows indicate examples of a "comet" with the nucleus containing unfragmented DNA and the electrophoretic migration of fragmented DNA (tail, shown in the inset of panel B).

Gene expression changes. We focused on the overexpressed genes because X-ray exposure can generally reduce gene expression. We found 74 genes significantly overexpressed $(\log \mathrm{FC}>2$, FDR $<0.05)$ after 2 hours from X-ray exposure (Tab. 1, Tab. 2S). Among these, 5 genes with a human ortholog (given in parentheses) are involved in DNA double-strand break repair mechanisms: TriadG28563 (RAD52), TriadG50031 (LIG4), TriadG53902 (DCLRE1C), TriadG25695 (RECQL5), TriadG61626 (XRCC6). Other genes such as TriadG55661, TriadG51590, TriadG50243 (POLB), TriadG51591, TriadG28268 (POLL), and TriadG57566 (LIG3) are involved in different mechanisms of DNA repair. Interestingly, the TriadG28470 $(E I F 41 B)$ radioresistant gene ${ }^{37}$ is overexpressed after treatment. In addition, we identified upregulated genes involved in signaling, microtubules activity, transporters, stress response, and other functions. There is marginal or no functional information for 20 of the overexpressed genes (Tab. 2S).

We focused on two genes: TP53 (TriadG64021) and MDM2 (TriadG54791), the main negative regulator of TP53, whose functions in the processes of apoptosis and oncogenesis is well known. MDM2 and TP53 genes are well conserved in T. adhaerens ${ }^{38}$. RNA-seq analysis

\begin{tabular}{|l|l|l|l|l|l|l|c|}
\hline \multicolumn{1}{|c|}{ Gene name } & logFC & P value & FDR & Gene name & logFC & P value & FDR \\
\hline TriadG62277 & $\mathbf{2 4 . 8 9}$ & $2.9 \mathrm{E}-09$ & $3.3 \mathrm{E}-05$ & TriadG18263 & $\mathbf{7 . 9 2}$ & $1.5 \mathrm{E}-04$ & $3.2 \mathrm{E}-02$ \\
\hline TriadG6927 & $\mathbf{1 3 . 4 8}$ & $4.0 \mathrm{E}-04$ & $4.4 \mathrm{E}-02$ & TriadG58306 & $\mathbf{7 . 8 9}$ & $1.2 \mathrm{E}-04$ & $3.0 \mathrm{E}-02$ \\
\hline
\end{tabular}




\begin{tabular}{|c|c|c|c|c|c|c|c|}
\hline TriadG51932 & 13.47 & $5.6 \mathrm{E}-05$ & $2.3 \mathrm{E}-02$ & |TriadG56741 & 7.86 & $4.6 \mathrm{E}-04$ & $4.7 \mathrm{E}-02$ \\
\hline TriadG28805 & 12.71 & $1.1 \mathrm{E}-05$ & $2.1 \mathrm{E}-02$ & TriadG54493 & 7.80 & $2.0 \mathrm{E}-04$ & $3.2 \mathrm{E}-02$ \\
\hline TriadG61077 & 12.23 & $1.3 \mathrm{E}-05$ & $2.1 \mathrm{E}-02$ & TriadG56088 & 7.80 & $1.2 \mathrm{E}-04$ & $3.0 \mathrm{E}-02$ \\
\hline TriadG30313 & 11.83 & $2.2 \mathrm{E}-05$ & $2.1 \mathrm{E}-02$ & TriadG57189 & 7.78 & $1.7 \mathrm{E}-04$ & $3.2 \mathrm{E}-02$ \\
\hline TriadG28548 & 11.08 & $1.9 \mathrm{E}-04$ & $3.2 \mathrm{E}-02$ & TriadG28470 & 7.77 & $4.9 \mathrm{E}-04$ & $4.9 \mathrm{E}-02$ \\
\hline TriadG2616 & 10.88 & $2.5 \mathrm{E}-05$ & $2.1 \mathrm{E}-02$ & TriadG52445 & 7.72 & $1.6 \mathrm{E}-04$ & $3.2 \mathrm{E}-02$ \\
\hline TriadG9891 & 10.50 & $5.4 \mathrm{E}-05$ & $2.3 \mathrm{E}-02$ & TriadG31423 & 7.67 & $1.8 \mathrm{E}-04$ & $3.2 \mathrm{E}-02$ \\
\hline TriadG51843 & 10.38 & $4.2 \mathrm{E}-05$ & $2.3 \mathrm{E}-02$ & TriadG51870 & 7.66 & $1.7 \mathrm{E}-04$ & $3.2 \mathrm{E}-02$ \\
\hline TriadG61611 & 10.17 & $5.2 \mathrm{E}-05$ & $2.3 \mathrm{E}-02$ & TriadG50031 & 7.66 & 4.9E-04 & $4.9 \mathrm{E}-02$ \\
\hline TriadG49741 & 10.12 & $6.1 \mathrm{E}-05$ & $2.3 \mathrm{E}-02$ & TriadG58144 & 7.62 & $2.4 \mathrm{E}-04$ & $3.5 \mathrm{E}-02$ \\
\hline TriadG60751 & 10.08 & $1.2 \mathrm{E}-04$ & $3.0 \mathrm{E}-02$ & TriadG28044 & 7.56 & $3.0 \mathrm{E}-04$ & $3.9 \mathrm{E}-02$ \\
\hline TriadG57566 & 9.80 & 5.7E-05 & $2.3 \mathrm{E}-02$ & TriadG49816 & 7.51 & $2.7 \mathrm{E}-04$ & $3.8 \mathrm{E}-02$ \\
\hline TriadG62635 & 9.60 & $2.4 \mathrm{E}-05$ & $2.1 \mathrm{E}-02$ & TriadG19828 & 7.49 & $1.9 \mathrm{E}-04$ & $3.2 \mathrm{E}-02$ \\
\hline TriadG53566 & 9.59 & $2.3 \mathrm{E}-04$ & $3.4 \mathrm{E}-02$ & TriadG60167 & 7.39 & $3.7 E-04$ & $4.4 \mathrm{E}-02$ \\
\hline TriadG8412 & 9.26 & $4.5 \mathrm{E}-05$ & $2.3 \mathrm{E}-02$ & TriadG58120 & 7.37 & $2.4 \mathrm{E}-04$ & $3.5 \mathrm{E}-02$ \\
\hline TriadG50911 & 9.25 & $7.8 \mathrm{E}-05$ & $2.6 \mathrm{E}-02$ & TriadG27148 & 7.30 & 2.7E-04 & $3.8 \mathrm{E}-02$ \\
\hline TriadG53185 & 9.24 & $3.0 \mathrm{E}-04$ & $3.9 \mathrm{E}-02$ & TriadG53902 & 7.30 & $1.6 \mathrm{E}-04$ & $3.2 \mathrm{E}-02$ \\
\hline TriadG56959 & 9.22 & $1.0 \mathrm{E}-04$ & $3.0 \mathrm{E}-02$ & TriadG62514 & 7.27 & 3.7E-04 & $4.4 \mathrm{E}-02$ \\
\hline TriadG63511 & 9.16 & $4.3 \mathrm{E}-05$ & $2.3 \mathrm{E}-02$ & TriadG51797 & 7.25 & $2.8 \mathrm{E}-04$ & $3.8 \mathrm{E}-02$ \\
\hline TriadG62773 & 8.99 & $6.0 \mathrm{E}-05$ & $2.3 \mathrm{E}-02$ & TriadG25695 & 7.24 & $2.0 \mathrm{E}-04$ & $3.2 \mathrm{E}-02$ \\
\hline TriadG55476 & 8.98 & $5.2 \mathrm{E}-04$ & $5.0 \mathrm{E}-02$ & TriadG20735 & 7.19 & $2.6 \mathrm{E}-04$ & 3.7E-02 \\
\hline TriadG28268 & 8.91 & $1.9 \mathrm{E}-05$ & $2.1 \mathrm{E}-02$ & TriadG30401 & 7.16 & $3.9 \mathrm{E}-04$ & $4.4 \mathrm{E}-02$ \\
\hline TriadG56020 & 8.48 & $5.4 \mathrm{E}-04$ & $5.0 \mathrm{E}-02$ & TriadG56259 & 7.14 & $1.4 \mathrm{E}-04$ & $3.1 \mathrm{E}-02$ \\
\hline TriadG55798 & 8.38 & 7.4E-05 & $2.6 \mathrm{E}-02$ & TriadG52125 & 7.05 & $1.4 \mathrm{E}-04$ & $3.1 \mathrm{E}-02$ \\
\hline TriadG28563 & 8.37 & $5.3 \mathrm{E}-05$ & $2.3 \mathrm{E}-02$ & TriadG55661 & 7.04 & $3.5 \mathrm{E}-04$ & $4.3 \mathrm{E}-02$ \\
\hline
\end{tabular}




\begin{tabular}{|l|c|c|c|l|l|l|l|}
\hline TriadG23897 & $\mathbf{8 . 3 5}$ & $2.1 \mathrm{E}-04$ & $3.3 \mathrm{E}-02$ & TriadG52757 & $\mathbf{6 . 9 6}$ & $3.7 \mathrm{E}-04$ & $4.4 \mathrm{E}-02$ \\
\hline TriadG57629 & $\mathbf{8 . 3 3}$ & $1.1 \mathrm{E}-04$ & $3.0 \mathrm{E}-02$ & TriadG30441 & $\mathbf{6 . 9 1}$ & $2.9 \mathrm{E}-04$ & $3.9 \mathrm{E}-02$ \\
\hline TriadG4311 & $\mathbf{8 . 2 7}$ & $1.2 \mathrm{E}-04$ & $3.0 \mathrm{E}-02$ & TriadG63052 & $\mathbf{6 . 8 8}$ & $3.9 \mathrm{E}-04$ & $4.4 \mathrm{E}-02$ \\
\hline TriadG60371 & $\mathbf{8 . 2 2}$ & $4.0 \mathrm{E}-04$ & $4.4 \mathrm{E}-02$ & TriadG51590 & $\mathbf{6 . 8 8}$ & $2.1 \mathrm{E}-04$ & $3.3 \mathrm{E}-02$ \\
\hline TriadG33759 & $\mathbf{8 . 1 9}$ & $3.7 \mathrm{E}-04$ & $4.4 \mathrm{E}-02$ & TriadG28067 & $\mathbf{6 . 8 7}$ & $2.6 \mathrm{E}-04$ & $3.7 \mathrm{E}-02$ \\
\hline TriadG63557 & $\mathbf{8 . 1 3}$ & $2.0 \mathrm{E}-04$ & $3.2 \mathrm{E}-02$ & TriadG52074 & $\mathbf{6 . 6 1}$ & $5.3 \mathrm{E}-04$ & $5.0 \mathrm{E}-02$ \\
\hline TriadG58689 & $\mathbf{8 . 1 0}$ & $1.8 \mathrm{E}-04$ & $3.2 \mathrm{E}-02$ & TriadG56514 & $\mathbf{6 . 4 6}$ & $5.3 \mathrm{E}-04$ & $5.0 \mathrm{E}-02$ \\
\hline TriadG61626 & $\mathbf{8 . 0 5}$ & $4.1 \mathrm{E}-04$ & $4.4 \mathrm{E}-02$ & TriadG50243 & $\mathbf{6 . 4 1}$ & $3.8 \mathrm{E}-04$ & $4.4 \mathrm{E}-02$ \\
\hline TriadG59637 & $\mathbf{8 . 0 3}$ & $1.3 \mathrm{E}-04$ & $3.0 \mathrm{E}-02$ & TriadG51591 & $\mathbf{6 . 3 7}$ & $5.2 \mathrm{E}-04$ & $5.0 \mathrm{E}-02$ \\
\hline TriadG60882 & $\mathbf{7 . 9 8}$ & $1.3 \mathrm{E}-04$ & $3.0 \mathrm{E}-02$ & TriadG53288 & $\mathbf{6 . 3 2}$ & $4.9 \mathrm{E}-04$ & $4.9 \mathrm{E}-02$ \\
\hline
\end{tabular}

Table 1. Genes overexpressed after 2 hours following X-ray exposure. Seventeen Five genes are overexpressed in relation to the expression in the control samples, $\log \mathrm{FC}=\log _{2}$ relative fold change. We used the false discovery rate (FDR) correction for multiple comparisons.

suggests that MDM2 is overexpressed (20-fold), while the expression of TP53 is similar to its expression in controls. Thus, we conducted additional experiments to investigate $M D M 2$ and TP53 genes' expression, exposing the animals to 240 Gy of X-rays. The RNA was extracted at different times after being exposed to X-rays (2, 6, 12, 24, 48 hours). MDM2 and TP53 genes' expression was analyzed by real-time PCR. We found that the expression of MDM2 was higher (12-fold) after two hours from the beginning of the experiment and decreased over time. On the other hand, the expression of TP53 was lower and indistinguishable from the controls across all time points (Mann-Whitney test, MDM2 vs control, $\mathrm{p}<0.05$; TP53 vs control, p=NS, Fig. 7). 


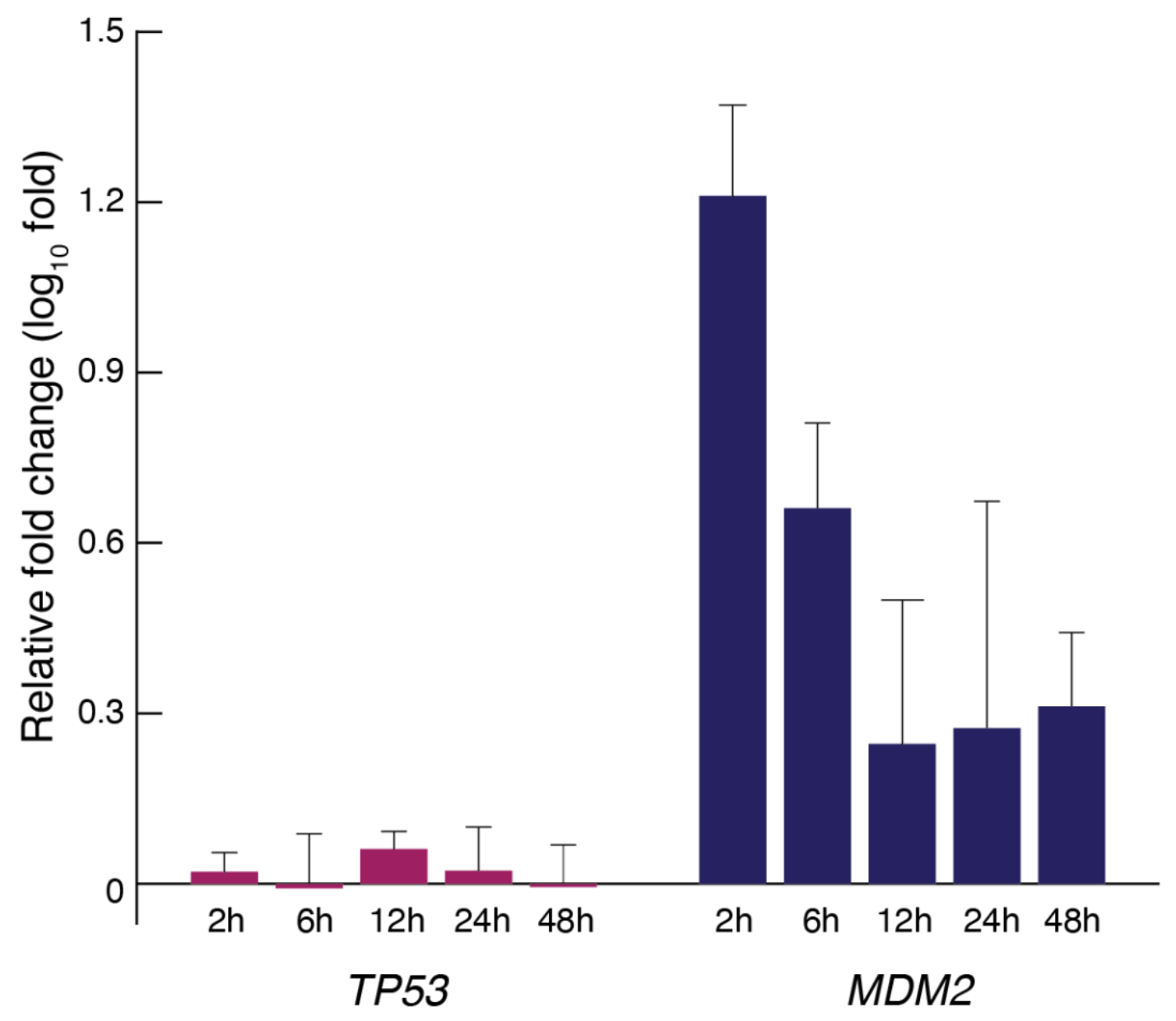

Figure 7. Change in TP53 and MDM2 gene expression in T. adhaerens after X-ray exposure. Each experiment was repeated thrice (Mann-Whitney test, MDM2 vs control, p<0.05; TP53 vs control, $\mathrm{p}=\mathrm{NS}$; TP53 vs MDM2, paired t-test, $\mathrm{P}<0.05)$. Histograms represent the mean $\left(\log _{10}\right.$ fold) \pm s.e.m. (error bars).

DNA sequencing of $\boldsymbol{T}$. adhaerens and extruded buds. We sequenced the genomes of two pairs of parental animals and their extruded bodies (as well as a viable, smaller T. adhaerens derived from an asymmetric fission of the first parental animal). We found an average of 930 mutations per $\mathrm{Mb}$. In regions of the genome where both parent samples had at least 10X converge, $24.5 \%$ of the detected mutations were shared, suggesting that the majority of detected mutations were 
caused by the X-ray exposure. The coverage was not sufficient to compare parental genomes and the extrusions. However, we did find a statistically significant enrichment of mutations in the apoptosis pathway, $\mathrm{FE}=1.88, \mathrm{FDR}=0.017$ for the pooled 5 samples.

\section{Discussion}

We found that $T$. adhaerens are particularly resilient to DNA damage, which may explain why there have been no reports of cancer in placozoans. Mice die when exposed to 10 Gray of radiation $^{39,40} .3-7$ Gy of X-rays induces severe DNA damage in mammalian cells ${ }^{41}$ and 6 Gy is almost always fatal for humans ${ }^{42}$. In contrast, cancer cell cultures exposed to a cumulative dose of 60 Gy develop radioresistance ${ }^{43}$. What is fascinating about T. adhaerens is that despite extensive DNA damage, they survive and fully recover, and in the process, they extrude apparently damaged clusters of cells that eventually die.

T. adhaerens appear to be highly resistant to radiation. We found that some placozoa were able to survive extremely high levels (240 Gy) of radiation exposure. There are several possible mechanisms that might underlie this radiation resistance. Tardigrades are radioresistant due to mechanisms that prevent DNA damage in the first place ${ }^{44,45}$, which seems to be an adaptation to dehydration ${ }^{46}$. Dehydration is unlikely to have been an issue for sea creatures like T. adhaerens and their radiation resistance appears not to be due to preventing the DNA damage. In fact, $T$. adhaerens suffer extensive DNA damage from the X-rays, but rely on mechanisms to repair DNA and maintain tissues homeostasis. Also, it is possible that their asexual reproductive strategy of budding reproduction might allow them to make use of many of the same mechanisms to extrude mutated cells in response to radiation exposure. 


\section{Expression of DNA repair genes and apoptotic pathways increases after radiation}

exposure. T. adhaerens up-regulate genes involved in DNA repair, apoptosis, signaling, microtubules activity, transporters, stress response and radioresistance (Tab.1). In particular, our detection of increased expression of the radioresistance gene TriadG28470 (EIF41B) is a nice (positive control) validation of our experimental approach. Interestingly, TriadG53566 (SMARCE1), a gene associated with chromatin remodeling complexes SWI/SNF, is also overexpressed. SWI/SNF complexes are involved in a variety of biological processes, including DNA repair. There is also evidence that SMARCE1 has a tumor suppressor function ${ }^{47}$. The other genes that were overexpressed after X-ray exposure, with unknown or poorly-known functions may be related to DNA repair, tissue homeostasis or apoptosis. For instance, Triad28044 is a homolog of the human gene EMC2. The function of EMC2 is not well known in humans but our results suggest that at least one of its functions may be X-ray damage response.

We also found that, after radiation exposure, $M D M 2$, the negative regulator of $T P 53$, is overexpressed in T. adhaerens but TP53 expression does not increase. This may be an adaptation to prevent catastrophic levels of TP53-induced cell death after X-ray exposure, while the animal activates mechanisms of DNA and tissue repair. A possible interpretation of these results is that MDM2 represses TP53 activity soon after X-ray exposure. It is also possible that MDM2 has additional functions related to DNA repair ${ }^{48}$. Although $M D M 2$ is well conserved in evolution, neither Caenorhabditis elegans nor Drosophila melanogaster have MDM2 ${ }^{38}$, suggesting that $T$. adhaerens may be a particularly good model for studying apoptosis.

\section{T. adhaerens extrudes apparently damaged cells that subsequently die. One striking}

mechanism we observed for dealing with potentially damaged and mutated cells is extrusion of 
those cells. With the small number of samples and the large number of mutations, we did not have enough statistical power to identify systematic differences in parental and extruded cells. We did detect an over-abundance of mutations in apoptotic pathways, as well as over-expression of MDM2. This may be due to natural selection at the cell level - cells with those mutations and responses would tend to survive, while cells that lacked those mutations and responses probably died.

In T. adhaerens, X-ray exposure triggers cell extrusion but the resulting buds are not a form of asexual reproduction. Initially, it is difficult to distinguish extrusion of inviable cells from asexual budding, and so the number of animals seems to increase soon after X-ray exposure. But, as we followed those buds, we found that they almost always die (Fig. 4). This extrusion may be a tissue or organismal strategy to remove damaged cells from the main animal body. We hypothesize that this is a cancer suppression mechanism, extruding pre-malignant cells before they can threaten the organism. This capacity for extrusion of cells might be responsible for the absence of evidence of cancer in T. adhaerens.

While the use of extrusion to prevent cancer may seem only relevant to simple organisms, the majority of human cancers arise in epithelial tissues, where extrusion and shedding of damaged cells could be a strategy for eliminating cancerous growths (such as the tissues of the skin and gut). There are hints that similar processes of extrusion of oncogenic cells may be at work in human cancer resistance ${ }^{49-52}$. Apoptotic cells and over-proliferating cells can trigger extrusion ${ }^{49-52}$. The Sphingosine 1-Phosphate pathway contributes to its regulation and is accomplished through cytoskeleton remodeling ${ }^{53}$.

The extrusion process is highly conserved in evolution ${ }^{49-52}$. Extrusion is involved in development, initiating cell differentiation, and epithelial-mesenchymal transitions in different 
organisms ranging from invertebrates to vertebrates ${ }^{54}$. Bacterial infection stimulates shedding, suggesting that cell extrusion is also a defensive mechanism against pathogens; in fact, bacteria can hijack the extrusion molecular mechanisms to invade underlying tissues ${ }^{54}$.

Cell cooperation (signaling) and competition are two important factors in extrusion ${ }^{54}$. Cell competition is a cell-elimination process through which cells can eliminate defective (e.g. growth rate, metabolic capacity) adjacent cells. The aberrant activation of signaling pathways in emergent cancer cells can be recognized by normal cells and triggers the elimination of the defective cells.

Cell competition could have a key role in Placozoa because these simple animals have not evolved a complex tissue organization. The extrusion of damaged cells may be a manifestation of cell-cell policing, a process that involves both cell competition and the regulation of cellular cooperation.

Extrusion of damaged cells is an understudied cancer suppression mechanism. At the moment, this process is only partially understood as it can only be studied in vivo in intact organisms. The opportunity to study cell extrusion in a simple animal model like T. adhaerens allows us to analyze the molecular mechanisms at the base of this process in detail. More broadly, extrusion may allow tissues to defend themselves against neoplastic cells; however, extrusion might also, in some cases, enable the spread of tumoral cellular aggregates in surrounding tissues and in the bloodstream, facilitating the formation of metastasis in advanced tumors. In fact, the metastatic efficiency of tumor cells increases when cells aggregate in multicellular clusters ${ }^{55}$. In this case, it is possible that what as originally a defense mechanism may be subverted by neoplasms in order to metastasize. Understanding this could potentially 
lead to interventions help shed pre-cancer cells, to prevent cancer, or alternatively, even suppress this extrusion process to help prevent metastasis.

Both T. adhaerens and extruded buds have high levels of mutation. The extremely high levels of DNA fragmentation and mutations caused by X-ray radiation suggests that $T$. adhaerens is either very good at repairing DNA or is simply able to tolerate high rates of mutations. The low number of samples sequenced do not allow us to draw conclusions pertaining to differences between the parental and extruded samples, but the impairment of apoptosis mechanisms alongside the activation of anti-apoptotic genes (e.g. MDM2) may prevent damaged cells from dying. T. adhaerens may avoid a massive loss of cells due to the extensive damage induced by X-rays by repairing or eliminating the damaged cells over the long term. Importantly, these pathways are well known to be impaired in cancer cells, suggesting that $T$. adhaerens could be a good model to study the mechanisms of carcinogenesis and cancer radioresistance.

Future work and alternative explanations for cell extrusion after radiation exposure. We have suggested that cell extrusion is likely a cancer resistance mechanism in T. adhaerens, however, it is possible that extrusion of cells does not have to do with cancer suppression. One alternative hypothesis that could be tested in future work is that cell extrusion may be a byproduct of $T$. adhaerens asexual fissioning reproductive biology, or even an adaptation to separate into fragments in response to stressors. The reduction of animal size could reduce metabolic demand, mitigating physicochemical stressors ${ }^{56}$ and allowing the organism to use more energy to repair cellular damage. Future work could explore these possibilities by deeper sequencing of the parental and extrusion DNA as well as mRNA. RNA expression should reveal 
if the extrusions are dying cells, neoplastic cells, or (damaged) juvenile organisms, which could be compared to T. adhaerens at different stages of reproduction, development and response to physicochemical stressors. Single-cell DNA sequencing could also reveal if the extrusions are a clonal or a heterogeneous collection of damaged cells.

\section{Conclusion}

Our experiments show that $T$. adhaerens is highly radiation resistant and that radiation exposure causes changes in the expression of genes associated with DNA repair and apoptosis. As a model system, it can potentially be used to identify new genes involved in fundamental processes associated with DNA repair, apoptosis regulation and tissue level cancer protection in vivo. Further, T. adhaerens is capable of extruding non-viable cells after radiation exposure, suggesting that the process of extrusion might be an important and understudied mechanism of cancer suppression. Together these results show promise for T. adhaerens as a model system for studying resilience to radiation exposure as well as the genetic and molecular mechanisms underlying DNA repair and apoptosis.

\section{References}

1. Aktipis, C. A. et al. Cancer across the tree of life: cooperation and cheating in multicellularity. Philos. Trans. R. Soc. Lond. B Biol. Sci. 370, (2015).

2. Tollis, M., Boddy, A. M. \& Maley, C. C. Peto's Paradox: how has evolution solved the problem of cancer prevention? BMC Biol. 15, 60 (2017).

3. Nunney, L., Maley, C. C., Breen, M., Hochberg, M. E. \& Schiffman, J. D. Peto’s paradox 
and the promise of comparative oncology. Philos. Trans. R. Soc. Lond. B Biol. Sci. 370, (2015).

4. Caulin, A. F. \& Maley, C. C. Peto's Paradox: evolution's prescription for cancer prevention. Trends Ecol. Evol. 26, 175-182 (2011).

5. Peto, R., Roe, F. J. C., Lee, P. N., Levy, L. \& Clack, J. Cancer and Aging in Mice and Men. Br. J. Cancer 32, 411-426 (1975).

6. Roche, B. et al. Natural resistance to cancers: a Darwinian hypothesis to explain Peto's paradox. BMC Cancer 12, 387 (2012).

7. Abegglen, L. M. et al. Potential Mechanisms for Cancer Resistance in Elephants and Comparative Cellular Response to DNA Damage in Humans. JAMA 314, 1850-1860 (2015).

8. Tollis, M. et al. Return to the sea, get huge, beat cancer: an analysis of cetacean genomes including an assembly for the humpback whale (Megaptera novaeangliae). Mol. Biol. Evol. (2019) doi:10.1093/molbev/msz099.

9. Dohrmann, M. \& Wörheide, G. Dating early animal evolution using phylogenomic data. Sci. Rep. 7, 3599 (2017).

10. Eitel, M., Guidi, L., Hadrys, H., Balsamo, M. \& Schierwater, B. New insights into placozoan sexual reproduction and development. PLoS One 6, e19639 (2011).

11. Schierwater, B. \& Eitel, M. Placozoa. in Evolutionary Developmental Biology of Invertebrates 1 107-114 (Springer, Vienna, 2015).

12. Schierwater, B. et al. Trichoplax and Placozoa: one of the crucial keys to understanding metazoan evolution. Key transitions in animal evolution 289, 326 (2010).

13. Smith, C. L. et al. Novel cell types, neurosecretory cells, and body plan of the early- 
diverging metazoan Trichoplax adhaerens. Curr. Biol. 24, 1565-1572 (2014).

14. Fortunato, A. \& Aktipis, A. Social Feeding Behavior of Trichoplax adhaerens. Frontiers in Ecology and Evolution 7, 19 (2019).

15. Pearse, V. B. \& Voigt, O. Field biology of placozoans (Trichoplax): distribution, diversity, biotic interactions. Integr. Comp. Biol. 47, 677-692 (2007).

16. Eitel, M. \& Schierwater, B. The phylogeography of the Placozoa suggests a taxon-rich phylum in tropical and subtropical waters. Mol. Ecol. (2010).

17. Spradling, A. et al. New roles for model genetic organisms in understanding and treating human disease: report from the 2006 Genetics Society of America meeting. Genetics 172, 2025-2032 (2006).

18. Wilson-Sanders, S. E. Invertebrate models for biomedical research, testing, and education. ILAR J. 52, 126-152 (2011).

19. Srivastava, M. et al. The Trichoplax genome and the nature of placozoans. Nature 454, 955-960 (2008).

20. Grell, K. G. \& Benwitz, G. Erg?nzende Untersuchungen zur Ultrastruktur von Trichoplax adhaerens F.E. Schulze (Placozoa). Zoomorphology 98, 47-67 (1981).

21. Schneider, C. A., Rasband, W. S. \& Eliceiri, K. W. NIH Image to ImageJ: 25 years of image analysis. Nat. Methods 9, 671-675 (2012).

22. Dhawan, A., Bajpayee, M. \& Parmar, D. Comet assay: a reliable tool for the assessment of DNA damage in different models. Cell Biol. Toxicol. 25, 5-32 (2009).

23. Bajpayee, M., Kumar, A. \& Dhawan, A. The Comet Assay: Assessment of In Vitro and In Vivo DNA Damage. in Genotoxicity Assessment 325-345 (Humana Press, Totowa, NJ, 2013). 
24. Sayers, E. W. et al. GenBank. Nucleic Acids Res. 47, D94-D99 (2019).

25. Team, R. C. \& Others. R: A language and environment for statistical computing. (2013).

26. Yates, A. D. et al. Ensembl 2020. Nucleic Acids Res. 48, D682-D688 (2020).

27. Mi, H. et al. Protocol Update for large-scale genome and gene function analysis with the PANTHER classification system (v.14.0). Nature Protocols vol. 14 703-721 (2019).

28. Pfaffl, M. W. A new mathematical model for relative quantification in real-time RT-PCR. Nucleic Acids Research vol. 29 45e-45 (2001).

29. Fortunato, A., Gasparoli, L., Falsini, S., Boni, L. \& Arcangeli, A. An analytical method for the quantification of hERG1 channel gene expression in human colorectal cancer. Diagn. Mol. Pathol. 22, 215-221 (2013).

30. Untergasser, A. et al. Primer3-new capabilities and interfaces. Nucleic Acids Research vol. 40 e115-e115 (2012).

31. Koressaar, T. \& Remm, M. Enhancements and modifications of primer design program Primer3. Bioinformatics 23, 1289-1291 (2007).

32. Andrews, S. FastQC: a quality control tool for high throughput sequence data. Available online. (2010).

33. Li, H. \& Durbin, R. Fast and accurate long-read alignment with Burrows-Wheeler transform. Bioinformatics 26, 589-595 (2010).

34. Geraldine_VdAuwera. Germline short variant discovery (SNPs + Indels). GATK-Forum https:/gatkforums.broadinstitute.org/gatk/discussion/11145/germline-short-variantdiscovery-snps-indels (2018).

35. Poplin, R. et al. Scaling accurate genetic variant discovery to tens of thousands of samples. bioRxiv 201178 (2017) doi:10.1101/201178. 
36. Cingolani, P. et al. A program for annotating and predicting the effects of single nucleotide polymorphisms, SnpEff: SNPs in the genome of Drosophila melanogaster strain w1118; iso-2; iso-3. Fly 6, 80-92 (2012).

37. Hayman, T. J. et al. Translation initiation factor eIF4E is a target for tumor cell radiosensitization. Cancer Res. 72, 2362-2372 (2012).

38. Lane, D. P. et al. Mdm2 and p53 are highly conserved from placozoans to man. Cell Cycle 9, 540-547 (2010).

39. Williams, J. P. et al. Animal models for medical countermeasures to radiation exposure. Radiat. Res. 173, 557-578 (2010).

40. Plett, P. A. et al. Establishing a murine model of the hematopoietic syndrome of the acute radiation syndrome. Health Phys. 103, 343-355 (2012).

41. Puck, T. T. \& Marcus, P. I. Action of x-rays on mammalian cells. J. Exp. Med. 103, 653666 (1956).

42. Wagner, R. H., Boles, M. A. \& Henkin, R. E. Treatment of radiation exposure and contamination. Radiographics 14, 387-396 (1994).

43. McDermott, N. et al. Fractionated radiation exposure amplifies the radioresistant nature of prostate cancer cells. Sci. Rep. 6, 34796 (2016).

44. Jönsson, K. I., Ingemar Jönsson, K., Harms-Ringdahl, M. \& Torudd, J. Radiation tolerance in the eutardigradeRichtersius coronifer. International Journal of Radiation Biology vol. 81 649-656 (2005).

45. Horikawa, D. D. et al. Radiation tolerance in the tardigrade Milnesium tardigradum. Int. J. Radiat. Biol. 82, 843-848 (2006).

46. Hashimoto, T. et al. Extremotolerant tardigrade genome and improved radiotolerance of 
human cultured cells by tardigrade-unique protein. Nat. Commun. 7, 12808 (2016).

47. Kehrer-Sawatzki, H., Farschtschi, S., Mautner, V.-F. \& Cooper, D. N. The molecular pathogenesis of schwannomatosis, a paradigm for the co-involvement of multiple tumour suppressor genes in tumorigenesis. Hum. Genet. 136, 129-148 (2017).

48. Eischen, C. M. Role of Mdm2 and Mdmx in DNA repair. J. Mol. Cell Biol. 9, 69-73 (2017).

49. Eisenhoffer, G. T. et al. Crowding induces live cell extrusion to maintain homeostatic cell numbers in epithelia. Nature 484, 546-549 (2012).

50. Slattum, G. M. \& Rosenblatt, J. Tumour cell invasion: an emerging role for basal epithelial cell extrusion. Nat. Rev. Cancer 14, 495-501 (2014).

51. Kajita, M. et al. Filamin acts as a key regulator in epithelial defence against transformed cells. Nat. Commun. 5, 4428 (2014).

52. Kajita, M. \& Fujita, Y. EDAC: Epithelial defence against cancer-cell competition between normal and transformed epithelial cells in mammals. J. Biochem. 158, 15-23 (2015).

53. Gu, Y.\& Rosenblatt, J. New emerging roles for epithelial cell extrusion. Curr. Opin. Cell Biol. 24, 865-870 (2012).

54. Ohsawa, S., Vaughen, J. \& Igaki, T. Cell Extrusion: A Stress-Responsive Force for Good or Evil in Epithelial Homeostasis. Developmental Cell vol. 44532 (2018).

55. Aceto, N. et al. Circulating tumor cell clusters are oligoclonal precursors of breast cancer metastasis. Cell 158, 1110-1122 (2014).

56. Passow, C. N., Arias-Rodriguez, L. \& Tobler, M. Convergent evolution of reduced energy demands in extremophile fish. PLoS One 12, e0186935 (2017).

Petralia, R. S., Mattson, M. P., \& Yao, P. J. 2014. “Aging and longevity in the simplest 
animals and the quest for immortality."Ageing research reviews, 16, 66-82.

\section{Acknowledgments}

We would like to thank Arathi Kulkarn and Avalon Yi for help with culturing the animals and assistance during the experiments. This work was supported in part by NIH grants U54 CA217376, U2C CA233254, P01 CA91955, R01 CA170595, R01 CA185138 and R01

CA140657 as well as CDMRP Breast Cancer Research Program Award BC132057 and the Arizona Biomedical Research Commission grant ADHS18-198847. The findings, opinions and recommendations expressed here are those of the authors and not necessarily those of the universities where the research was performed or the National Institutes of Health.

\section{Author contributions}

A. Fortunato A.A. and C.C.M. designed the study. A. Fortunato designed and performed the experiments, collected and analyzed the data. A. Fleming was an undergraduate student; she contributed to perform the experiments and collecting data. A. Fortunato, A.A. and C.C.M. wrote the manuscript.

\section{Competing interests}

The authors declare that they have no competing interests.

\section{Materials \& Correspondence}

Correspondence and requests for materials should be addressed to Angelo Fortunato 